\title{
Teaching conversational implicature to adult language learners
}

\author{
Polina Mitkova*
}

\begin{abstract}
Despite the widely-held belief that second/foreign language acquisition takes place more effortlessly in the early age, this paper aims to research the impact of the age factor in this process and to find out what adjustments need to be made in the teaching environment in order to optimize the second/foreign language acquisition for adult learners of English. The paper will address the topic of teaching particularized conversational implicature through the activity attached, because it gives a real example of what it means to know all the words of what one hears, but not to be prepared to respond in a socially acceptable manner. The aim of this paper is to equip adult learners with the linguistic formula "Not + very + positive adjective" that will help them overcome awkward situations that inhibit their engagement in communication, on the one hand, and, on the other, to prompt teachers to consider factors such as motivation, self-confidence and fixed-mindset that may considerably change the desired outcomes.
\end{abstract}

Key words: Conversational implicature, EFL learning, adults, discourse completion tasks.

\section{Introduction}

This paper focuses on teaching implicature in English to adult learners. When designing the materials I took into consideration individual differences (ID) in second language acquisition (SLA) and pragmatics as one can easily see the close connection between the two fields. Both in ID and in pragmatics there are numerous interpretations of our speech acts and the way messages are conveyed depends very much on the differences among individuals.

The title of the classroom activity is "How honest can you be?" It is aiming at drawing learners' attention to the fact that there is a significant amount of relativity regarding foreign language learning depending on individual differences such as age, gender, personality etc. According to Rauch (2003) extroverts tend to exhibit more readily and with wider audiences openness and sociability, while introverts thrive at deeper conversations with smaller contingent.

According to Obler (2005), in our language development there are to be observed a number of stages. He notes that "the language development in early childhood and even late childhood must be different from that of adulthood, however since there is probably a core language all children learn, whereas the

* PhD student in the Department of English Studies, University of Shumen, Shumen, Bulgaria 
special language registers and skills of adolescence and adulthood are relatively optional - only people who need them and find themselves exposed to them have a chance to acquire them".

It has been my observation that adult learners sometimes avoid speaking in English in awkward situations because they feel the possible risks embedded in the context. While young learners can afford to take the risk, because everyone can easily pardon their error and attribute it to lack of experience and their natural tendency to name things with their real names, adults are not usually exempt from taking responsibility for their actions.

For these reasons when designing this lesson plan (see Appendix 1) and tasks (see Appendix 2) I aimed at equipping adult learners with the skills to give comment in situations when it is not advisable to be extremely honest e.g. "Your car is not very big." to be preferred over "Your car is small."

The pragmatic component that was chosen is conversational implicature, defined by Yule (1996) as "an additional unstated meaning that has to be assumed" in order to maintain the conversation. Although there are many kinds of implicatures that deserve attention, the one I will focus on is called "particularized conversational implicature". It differs from the other implicatures in that it requires the participants in the spoken exchange to recognize the inferences in the particular conversation so that they can work out the conveyed meaning. I believe that it deserves more attention, because unlike the other implicatures, it is more particular and tied up with the specifics of the spoken exchange and its contextual factors. My experience so far with ESL/EFL learners is that although they sometimes recognize it, they are not able to respond appropriately to it and as a result give a false impression to the other participants in the conversation. My attention will be directed to teaching implicature for situations with higher degree of consequentiality, which require more tactfulness and politeness. I believe that this will equip learners with skills to convey more appropriately their intended messages and give them a greater satisfaction, which is an important factor for their motivation to improve their English skills.

\section{Time}

The lesson is designed for a time frame of 60 minutes and will not require anything but their worksheet and common stationery. Depending on the pace of the students and their experience with such ID/pragmatics focused lessons it might require additional time to put them in the right frame of mind.

\section{Target students and context}

The target group of students is adult learners of English, mainly professionals, with proficiency level of intermediate and above. This lesson will be most suited 
as a part of a speaking course or four-skill integrated course with focus on pragmatic awareness taught on one-to-one basis or small classes. It will focus on teaching the productive skills of writing, and as a sub-skill that can be further developed outside my current lesson time frame - speaking. The learners will be mainly speakers of Japanese or other European languages. The lesson that is designed draws a lot on awareness-raising tasks.

\section{Background/ rationale for the activity design}

The ID variable chosen for this activity is age. Since most of the students are older adults ( 25 years of age and above) I was interested to find out how one can deal with the age factor in a more professional manner. According to Schleppegrell (1987: 1) "there is no decline in the ability to learn as people get older", but the means by which the second language learning needs to take place have to be adjusted in accordance to the changes that take place as individuals advance in years.

Contrary to popular stereotypes, older adults can be good foreign language learners. The difficulties they experience in the language classroom can be overcome through adjustments in the learning environment, attention to the affective factors, and the use of effective teaching methods (Schleppegrell 1987: 1). She argues that if we have healthy learners with no hearing or visual impairments, we can expect from them to have "highly-developed cognitive systems", to be able to make "higher order associations and generalizations and to integrate new language input with their already substantial learning experience. They rely on long-term memory rather than short-term memory function used by children and young learners for rote learning." For this reason she recommends avoiding oral drills and memorizations and trying "integrating new concepts and materials into already existing cognitive structures" instead. She warns against fast-paced lessons and competitive exercises as they may reinforce the affective barriers.

Affective factors such as motivation and self-confidence are very important in language learning. Many older learners fear failure more than their younger counterparts, maybe because they accept the stereotype of the older learner as a poor language learner or because of previous unsuccessful attempts (ibid.).

In order to help students succeed in the classroom, teachers may consider Dweck's work (2006) on students' mindsets. Learners with a fixed mindset believe that intelligence is a fixed trait that cannot be developed and tend to look at mistakes as a confirmation of that statement. On the other hand, students with growth mindsets view mistakes as an inevitable stage towards perfection.

A possible step towards promoting the growth mindset may be to avoid activities that include expectation of error-free speech and extensive pronunciation correction at the beginning, and focus on providing students with opportunities 
to work together and acquire receptive skills first.

Schleppegrell (1987) makes the point that adult learners in profession have very urgent work- or real life-related language needs. "They are not willing to tolerate boring or irrelevant content" and "need materials designed to present structures and vocabulary that will be of immediate use to them". When designing the material I was trying to keep the language in it very relevant to everyday life. I meant my initial questions to represent different aspects of their lives - personal tricky situations and work situations with superiors.

Detailed description of the activity including possible expansions and variations

The lead-in motivation phase of the lesson is designed as a personality test entitled "How honest can you be?" Students are given three different tricky situations (see Appendix 2, task 1) and asked to literally translate their responses in English from their mother tongue for each one of them. The three situations are introduced in the form of a discourse completion task (DCT).

According to Eslami-Rasekh (2005) starting by literal translation of speech acts clearly shows students that "pragmatic translation of instances of language use can be challenging". On the other hand, doing that at the beginning validates the learners L1 as a useful resource and not merely as a "negative factor to be endured" (Cook 1999). It also shows that "the emphasis is first on pragmatics rather than on English" (ibid.). Output tasks also facilitate students noticing forms they lack in L2.

At the end of the task 1 students are encouraged to think of and share situations when they did not feel comfortable saying what they really thought or felt. According to McLean (2005) to make the content of the lesson more authentic it is best if the teacher invites the students to generate their own DCTs. Contribution from students also aims at sharpening their interest and training them to be good observers.

In the second task (task 2) students are presented with data from native speakers (NS) of English and asked to look for the differences and similarities. In the following task 3 they are asked to think of categories they can put the presented responses into.

According to Swain's output hypothesis (Swain 1998) when learners are to produce certain structures for which they lack knowledge - pragmalinguistic or sociopragmatic as it may be in our case, they turn to the relevant sources in order to fill their gaps. Directing the learners' attention to the linguistic form is in accordance with Schmidt's noticing hypothesis (Schmidt 1993) as well.

Arranging the NS's answers in categories further direct students' attention about the variety of ways there are to react to the tricky situations given in 
the personality test. Looking for common features in the answers in all the scenarios aims to further raise their awareness of the target structures. As it may be challenging to come up with captions for the categories, such have been provided in the worksheet. Students are only to match the caption to the situation.

The next task 4 is to evaluate the contextual factors - status, distance, imposition, for each of the three situations. It is aiming at raising students' pragmatic awareness in an inductive way through guided self-discovery. The task is designed to be used as an opportunity for explicit teaching of relevant pragmatic metalanguage - distance, status, imposition/consequentiality.

As pointed out by Ishihara (in press) "merely exposing students to contextualized input is unlikely to lead to students' learning of pragmatics...classroom tasks will have more of a payoff to learning if the language forms and the relevant contextual features are highlighted and if the relationship between them is explored". The aim of the lesson is not simply to notice and "register the simple occurrence of some event" (Schmidt 1993 as cited by Ishihara), but to reach the understanding stage when learners can recognize the principles, rules or patterns.

After the students have tried their hand at analyzing the target feature, the inductive phase comes to a close and they are provided with the sociopragmatic and pragmalinguistic information in a deductive explicit manner, because as it was pointed above the explicit approach aiming at analyzing both context and form was found to be more effective than implicit teaching. Presenting them with the sociopragmatic and pragmalinguistic pattern ensures that they are not left wondering if they arrived at the right results during the awareness-raising stage of the task.

The rule given in the deductive explicit teaching section contains a metalanguage term (adjectives with positive/negative connotations) that is elaborated on in the following exercise. Students are asked to think of adjectives with negative connotations, or put in simple words "adjectives that you do not want to hear used about yourself". After they are able to generate some examples, they are asked to form collocations - adj. + noun phrases with some of the adjectives they have in their list. When they have completed this task (task 5), they have to go to the next step where they are required to rewrite the collocations using positive adjectives and write sentences with the new collocations. The goal here will be to keep the negative idea as expressed in the initial collocation, but using the sociopragmatic and pragmalinguistic knowledge they gained to modify them so that they do not sound so direct and offending.

The goal here is to consistently guide them through the steps of turning a negatively-laden statement/thought into a more pragmatically acceptable 
utterance. This is done so that the pattern that they have been introduced to is further reinforced. The grounds for providing a lot of scaffolding for the learners at the initial stages come from Vygotsky's sociocultural theory (Vygotsky 1978) stipulating that "cognitive development occurs in interaction with others with more advanced cognitive ability (e.g., a teacher or a more capable peer) through language-mediated activity rather than in isolation". A key concept in his theory is the zone of proximal development (ZPD), whose expansion needs to be targeted by the teachers or the more capable peers through the scaffolding process.

Although not incorporated in the outline of the lesson plan assessment is designed to take place when eliciting students' reactions in similar tricky situations as the ones listed in the lesson. When I taught this target structure before, in the following lessons I created authentic scenarios and I asked for my students' opinion or reaction that was to draw on the newly-acquired pragmatic knowledge and observed their behavior in their casual conversations. Although I have not done research on the frequency of the structure I noticed that it appears quite often in daily conversation and my students were giving their reactions with a slight grin on their faces, which was a significant enough indicator for me.

\section{Desired outcomes, possible obstacles and limitations}

The overall goal of the lesson is to teach the productive skills of speaking and writing, but because it draws a lot on awareness-raising activities the receptive skills are also integrated.

The specific goals of the lesson are to equip students with more pragmalinguistic knowledge so that they are able to successfully use the structure "Not + very + positive adjective" to convey messages with negative connotation in a tactful manner. The sociopragmatic knowledge they acquire is to be able to differentiate the context when using the target structure is advisable and when it can be ignored.

\section{Conclusion}

In conclusion, this paper was an effort to apply individual differences and pragmatics in SLA. The goal was to consider the age factor when teaching EFL/ ESL students how to use conversational implicature.

The observations that have been made during the years when directing the learners' attention to the simple linguistic formula "Not + very + positive adjective" show that many of those, who are dealing with giving feedback or engaged more actively in communication, do incorporate it in their linguistic tools.

Another conclusion that can be made concerning the teaching methods for 
adults is that when the language teacher reduces the stress and the anxiety of failure in class, giving priority to confidence-building tasks and pairing them with enough linguistic tools to solve students' most burning linguistic needs, motivation is on the rise.

\section{References}

Cook 1999. Cook, V. "Going Beyond the Native Speaker in Language Teaching." TESOL Quarterly, 33/2, 1999. 185- 209.

Dweck 2006. Dweck, C. "Keeping Current Mindsets: How Praise is Harming Youth and What Can be Done About It?" School Library Media Activities Monthly, $24 / 5,2006.55-58$.

Eslami-Resekh 2005. Eslami-Resekh, Z. "Raising the Pragmatic Awareness of Language Learners.” ELT Journal, 59/ 3, 2005. 199-208.

Ishihara, Cohen (in press). Ishihara, N., A. D. Cohen, Teaching and Learning Pragmatics: Where Language and Culture Meet. Harlow, UK: Pearson/Education.

McLean 2005. McLean, T. "Why no tip?": Student-Generated DCTs in the ESL Classroom. In D. Tatsuki (Ed.), Pragmatics in Language Learning, Theory, and Practice (pp. 150156). Tokyo: Pragmatics Special Interest Group of the Japan Association for Language Teaching.

Obler 2005. Obler, L. “Language in Adulthood.” In Gleason, J. B. (Ed.) The Development of Language ( $6^{\text {th }}$ Ed.). Boston, Allyn and Bacon. 2005 [n.p.]

Rauch 2003. Rauch, J. Caring for Your Introvert. Retrieved from: http://www.theatlantic. com/magazine/archive/2003/03/caring-for-your-introvert/2696/

Schleppegrell 1987. Schleppegrell, M. “The Older Language Learner.” ERIC Clearinghouse on Languages and Linguistics Washington DC. 1987.1-6. http://files.eric.ed.gov/fulltext/ ED287313.pdf

Schmidt 1993. Schmidt, R. "Consciousness, Learning and Interlanguage Pragmatics.” In G. Kasper, S. Blum-Kulka (Eds.), Interlanguage pragmatics, Oxford: OUP, 1993. 21-42.

Swain 1998. Swain, M. "Focus on Form Through Conscious Reflection." In C. Doughty, J. Williams (Eds.), Focus on Form in Classroom Second Language Acquisition. Cambridge: CUP, 1998.

Vygotsky 1978. Vygotsky, L. S. Mind in society: The development of higher psychological processes. Cambridge, MA: Harvard University Press, 1978.

Yule 1996. Yule, G. Pragmatics. Oxford, England: Oxford University Press, 1996. 


\section{Appendix 1}

\section{LESSON PLAN}

Teacher: Polina Mitkova

Age: adults

Level: Intermediate/Upper Intermediate/Advanced

Lesson type: Writing/Speaking

Teaching materials: "How honest can you be?"- a worksheet designed by the teacher for the purposes of raising pragmatic awareness.

Background of the students: The students are adults, mainly professionals who have been abroad and speak quite well, but need some small corrections; They have already encountered certain awkward situations and would appreciate some instruction in pragmatics since not knowing how to react in a socially acceptable manner is blocking them and affecting their confidence of fluent English speakers; The average age is over 35 years.

Main aim: To improve the socializing skills of learners in English

To raise awareness of some strategies for avoiding awkward situations used by native speakers.

To raise awareness of the linguistic formula "Not + very + positive adjective" used for the same purposes

Subsidiary aims: To have fun while completing DCT-oriented tasks.

To help students recognize their reactions better.

Time: $60 \mathrm{~min}$

Assumptions: The idea of avoiding awkward situations will definitely appeal to students, since most of them have faced the same or similar scenarios and struggled with finding a way out without offending the others.

Anticipated problems and possible solutions: Students may not be aware of the pragmatic aspects of language and it may take a while until they get used to the format of using discourse completion tasks. A way to overcome the initial difficulties is to explain that this is not going to be a typical English lesson and students will have to use their memories of similar cases to the classroom. 


\begin{tabular}{|c|c|c|c|}
\hline Stage / Procedure & $\begin{array}{c}\text { Interaction } \\
\text { pattern }\end{array}$ & Timing & Objectives \\
\hline $\begin{array}{l}\text { 1. Introduce the idea of being honest } \\
\text { and the way it affects the use of } \\
\text { language. } \\
\text { 2. Elicit examples from Ss experience. }\end{array}$ & $\begin{array}{l}T \\
T-S s\end{array}$ & $3-5 \min$ & $\begin{array}{l}\text { To activate Ss schemata and lead them } \\
\text { in the topic }\end{array}$ \\
\hline $\begin{array}{l}\text { 3. Ss read the cases presented and } \\
\text { are asked to translate literally their } \\
\text { responses into English from their } \\
\text { mother tongue for each one of the } \\
\text { cases (task 1) }\end{array}$ & $\mathrm{T}-\mathrm{Ss}$ & $10 \mathrm{~min}$ & $\begin{array}{l}\text { To shows Ss that "pragmatic translation } \\
\text { of instances of language use can be } \\
\text { challenging" (Eslami-Rasekh 2005). } \\
\text { To validate the learners L1 as a useful } \\
\text { resource and not merely as a "negative } \\
\text { factor to be endured" (Cook 1999). } \\
\end{array}$ \\
\hline $\begin{array}{l}\text { 4. Ss are encouraged to share } \\
\text { situations when they did not feel } \\
\text { comfortable saying what they really } \\
\text { thought or felt. }\end{array}$ & $\mathrm{T}-\mathrm{Ss}$ & $10 \mathrm{~min}$ & $\begin{array}{l}\text { To show that "the emphasis is first on } \\
\text { pragmatics rather than on English" } \\
\text { (ibid.). } \\
\text { To make the content of the lesson more } \\
\text { authentic and personalised. } \\
\text { To encourage Ss to generate their own } \\
\text { DCTs. }\end{array}$ \\
\hline $\begin{array}{l}\text { 5. Ss are presented with data from } \\
\text { native speakers (NS) of English and } \\
\text { asked to look for the differences and } \\
\text { similarities (task 2) with their own } \\
\text { ones. }\end{array}$ & $\mathrm{T}-\mathrm{Ss}$ & $5 \mathrm{~min}$ & $\begin{array}{l}\text { To sharpen their interest and train them } \\
\text { to be good observers. }\end{array}$ \\
\hline $\begin{array}{l}\text { 6. Ss are asked to categorize } \\
\text { the presented responses (task } 3 \text { ) } \\
\text { under the captions provided in the } \\
\text { worksheet. }\end{array}$ & Ss & $3 \min$ & $\begin{array}{l}\text { To facilitate Ss noticing forms they lack } \\
\text { in L2. }\end{array}$ \\
\hline $\begin{array}{l}\text { 7. Ss are to evaluate the contextual } \\
\text { factors - status, distance, imposition } \\
\text { for each of the three situations (task } \\
\text { 4). }\end{array}$ & Ss & $5 \min$ & $\begin{array}{l}\text { To raise Ss pragmatic awareness in } \\
\text { an inductive way through guided self- } \\
\text { discovery. To direct Ss attention to } \\
\text { the relevant pragmatic metalanguage } \\
\text { - distance, status, imposition/ } \\
\text { consequentiality. }\end{array}$ \\
\hline $\begin{array}{l}\text { 8. Teach the metalanguage } \\
\text { terms (adj. with positive/negative } \\
\text { connotation) and ask Ss to think of } \\
\text { adj. with negative connotations and } \\
\text { to form collocations - adj. + noun } \\
\text { phrases with some of the adj. they } \\
\text { have in their list (task 5). }\end{array}$ & $\mathrm{T}$ & $17 \mathrm{~min}$ & $\begin{array}{l}\text { To introduce deductive teaching } \\
\text { to bring clarity to Ss who might be } \\
\text { confused. }\end{array}$ \\
\hline $\begin{array}{l}\text { 9. Ss rewrite the negative collocations } \\
\text { using positive adjectives and write } \\
\text { sentences with the new collocations. }\end{array}$ & Ss & $5-7 \min$ & $\begin{array}{l}\text { To encourage Ss to generate their own } \\
\text { collocations. } \\
\text { To help Ss turn a statement } \\
\text { with negative connotation into a } \\
\text { pragmatically acceptable one. }\end{array}$ \\
\hline
\end{tabular}




\section{Appendix 2}

\section{HOW HONEST CAN YOU BE?}

Task 1 Translate directly into English your answers to the following situations

1. Your friend at work sneaks into your office after the meeting is over and asks for your opinion. You are not particularly fond of his/her idea. S/he says to you: "Wasn't that brilliant?"

YOU:

2. You are a school owner and one of the teachers who work for you has discipline problems and you went in one of his classes for observation. You noticed that he is putting the naughty students down too much, even abuses them verbally sometimes. You would like to suggest that he makes some changes. He says: "I think I have to be strict with them. They are not paying attention at all and calling me names!"

YOU:
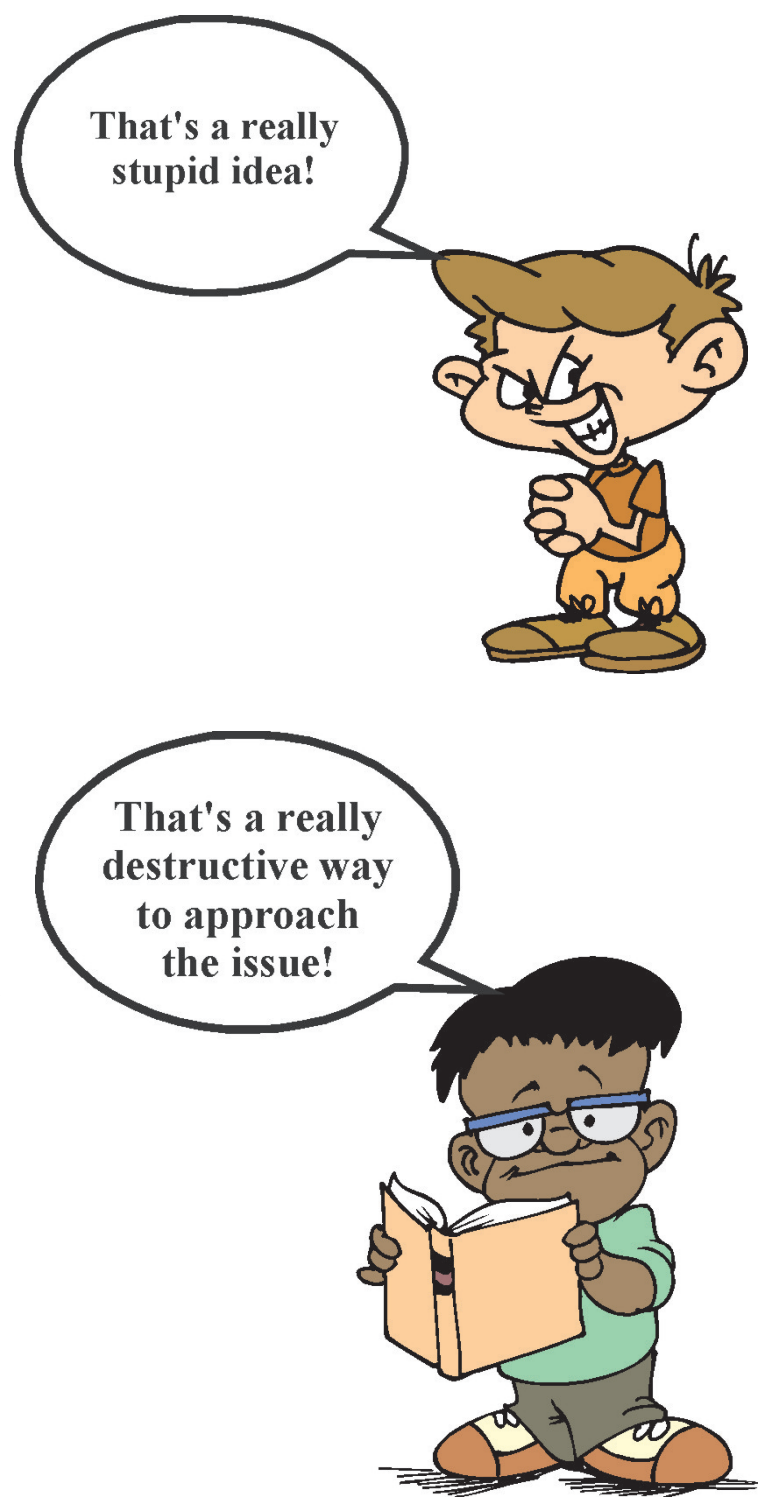
3. Your mom cooked your favorite meal. After you tried it, you are very disappointed, because it tastes really bad this time and you are not sure you can finish it. She says: "Don't you like it?" YOU:

Now it is your wife who

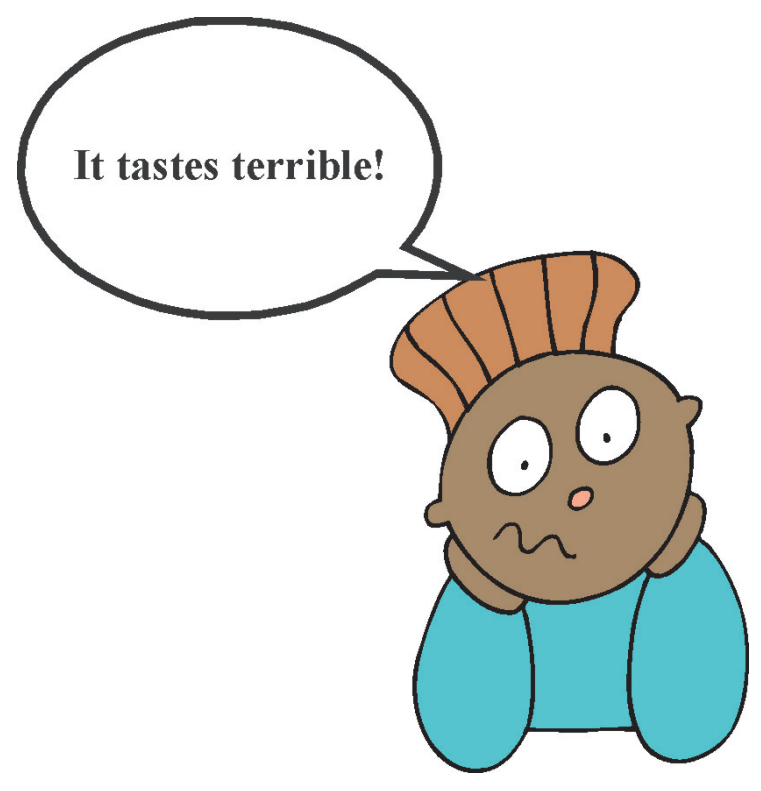
cooked the meal.

YOU:

Can you think of other situations when you found it difficult to be completely honest?

Task 2 Now compare your answers with those of fluent English speakers.

What are some of the similarities/differences?

1. a. That's not a very good idea!

b. That's stupid! Are you crazy?! 
c. Are you drunk?

2. a. I think we have to approach it in another way!

b. That's not a very constructive approach!

3. a. I am not hungry!

b. Mm, did you cook it long enough?

c. Did you put enough salt?

d. A male said they will not say anything no matter how bad the food is, because of a rule he grew up with, that anything put on the plate must be eaten.

f. Another male said that if it doesn't happen often he will avoid addressing the issue as cooking is as sensitive for women as driving skills are for men.

Task 3 Now sort these statements into categories. Do you see some patterns?

\begin{tabular}{|l|l|l|l|}
\hline $\begin{array}{l}\text { use adj. with apositive } \\
\text { connotation }\end{array}$ & say what you think & $\begin{array}{l}\text { avoid talking about } \\
\text { it, follow the usual } \\
\text { routine as if nothing } \\
\text { happened }\end{array}$ & $\begin{array}{l}\text { ask a relevant/related } \\
\text { question }\end{array}$ \\
\hline & & & \\
\hline & & & \\
\hline
\end{tabular}

Task 4 Now for each situation try to evaluate what is the:

a) social/psychological distance between the speaker and you - Close or Distant?

\begin{tabular}{|l|l|l|l|}
\hline Situation 1 & Situation 2 & Situation 3 & Situation 4 \\
\hline C---------------D & C---------------D & C--------------D & C--------------D \\
\hline
\end{tabular}

b) consequentiality - is it Low or High? 


\begin{tabular}{|l|l|l|l|}
\hline Situation 1 & Situation 2 & Situation 3 & Situation 4 \\
\hline L---------------H & L---------------H & L---------------H & L--------------H \\
\hline
\end{tabular}

c) The relative social status of the speakers (e.g. age, gender, role in a dialogue, etc.) - is it Low or High?

\begin{tabular}{|l|l|l|l|}
\hline Situation 1 & Situation 2 & Situation 3 & Situation 4 \\
\hline S1 L------------H & S1 L-------------H & S1 L------------H & S1 L------------H \\
S2 L----------H & S2 L----------H & S2 L----------H & S2 L---------H \\
\hline
\end{tabular}

One way to be tactful and avoid being too direct with people of higher status or who are not very close to you is by using a negative (e.g. "not") along with adjectives with positive connotations (positive adjectives) as in:

"The hotel was not very clean!" instead of "The hotel was dirty!"

Not + very + positive adjective

Task 5 In pairs, think of five adjectives that you do not want other people to use about yourself or something that you have or say - e.g. boring, stupid etc.

1.

3.

.

4.

5.

Share them with the other students in class. Choose three adjectives and add nouns to them to make commonly used phrases - e.g. a stupid question. 
1.

2.

3.

Now think of three adjectives with the opposite meaning of the ones you chose above (e.g. stupid - smart) and rewrite the phrases above. Then write sentences with new phrases. Keep the idea as it was expressed in the initial phrase, but using the knowledge you gained try to modify them so that they do not sound so direct and offending - e.g. That was a stupid idea/ That was not a very smart idea.

1.

2 .

3. 